\title{
Passifloraceae sensu stricto do Parque Estadual Cachoeira da Fumaça, Espírito Santo, Brasil ${ }^{1}$
}

Passifloraceae sensu stricto from Parque Estadual Cachoeira da Fumaça, Espírito Santo, Brazil

\author{
Katiuss Ferreira Borges ${ }^{2}$ \& Michaele Alvim Milward-de-Azevedo ${ }^{3}$
}

\begin{abstract}
Resumo
O Parque Estadual Cachoeira da Fumaça (PECF) está localizado na divisa dos municípios de Alegre e Ibitirama, situado na região do Caparaó, sul do Espírito Santo, protegendo nascentes e remanescentes de um trecho conservado do rio Braço Norte Direito, afluente do rio Itapemirim. Neste trabalho são apresentadas as espécies de Passifloraceae stricto sensu ocorrentes no PECF. A família está representada pelo gênero Passiflora com seis espécies: Passiflora alata, P. amethystina, P. capsularis, P. edulis, P. porophylla e $P$. speciosa. São apresentadas descrições, fotos, dados de distribuição geográfica e palinotaxonomia, além de comentários taxonômicos das espécies.
\end{abstract}

Palavras-chave: Alegre, diversidade, Ibitirama, Passiflora, sul do Espírito Santo.

\begin{abstract}
The "Parque Estadual Cachoeira da Fumaça" (PECF) is located between Alegre and Ibitirama, region of Caparaó, South of Espírito Santo, protecting springs and remnants of a preserved section of the Braço Norte Direito river, affluent of the Itapemirim river. In this work, we are presented the species of Passifloraceae stricto sensu in the PECF. The family is represented for the genus Passiflora with six species: Passiflora alata, $P$. amethystina, P. capsularis, $P$. edulis, $P$. porophylla and $P$. speciosa. Descriptions, photos, geographic distribution data and palinotaxonomy, in addition taxonomic comments are presented.
\end{abstract}

Key words: Alegre, diversity, Ibitirama, Passiflora, South of Espírito Santo.

\section{Introdução}

Passifloraceae stricto sensu Juss. ex Roussel pertence a ordem Malpighiales (APG IV 2016) e engloba cerca de 630 espécies distribuídas em 16 gêneros (Deginani 1999; Judd et al. 2009; Santos et al. 2016). Com distribuição pantropical, podem ser encontrados maior número de representantes nas regiões tropicais e subtropicais das Américas e em menor proporção na África, Ásia e Austrália (Ulmer \& MacDougal 2004; Mäder et al. 2009).

Entre os gêneros, destaca-se Passiflora L. como o mais representativo, contemplando aproximadamente 520 espécies divididas em cinco subgêneros: Astrophea (DC.) Mast., Deidamioides (Harms) Killip, Decaloba (DC.) Rchb., Passiflora
(MacDougal \& Feuillet 2004), e Tetrapathea (DC.) P. S. Green, adicionado por Krosnick et al. (2009).

No Brasil podem ser encontrados quatro gêneros: Ancistrothyrsus Harms, Dilkea Mast., Mitostemma Mast. e Passiflora totalizando 153 espécies, e destas 87 são endêmicas (BFG 2015). No Espírito Santo são encontradas 31 espécies, sendo 22 endêmicas do Brasil, distribuídos em dois subgêneros: Mitostemma e Passiflora (BFG 2015).

No estado do Espírito Santo foi implementado o primeiro corredor de biodiversidade, o Corredor Central da Mata Atlântica, como iniciativa para o planejamento de conservação regional (Fonseca et al. 2004). Embora de uma importância ambiental indiscutível, não há muito conhecimento sobre a

\footnotetext{
${ }^{1}$ Parte da monografia apresentada pela primeira autora para obtenção do título de Bacharel em Ciências Biológicas, da Universidade Federal do Espírito Santo, Centro de Ciências Agrárias.

${ }^{2}$ Universidade Federal do Espírito Santo, Centro de Ciências Agrárias e Engenharias, Alto Universitário s/n, Guararema, 29500-000, Alegre, ES, Brasil. katiborgesbio@gmail.com

${ }^{3}$ Universidade Federal Rural do Rio de Janeiro, Inst. Três Rios, Depto. Ciências do Meio Ambiente, Av. Prefeito Alberto Lavinas 1847, Centro, 25802-100, Três Rios, RJ, Brasil. michaelemilward@gmail.com

${ }^{4}$ Autor para correspondência: michaelemilward@gmail.com
} 
flora desse estado, o que reforça a necessidade da realização de estudos florísticos, especialmente com Passifloraceae s.s., já que o conhecimento sobre a família no Espírito Santo está restrito às listagens publicadas por BFG (2015), Dutra et al. (2015) e Souza et al. (2016).

Este trabalho visa realizar um estudo taxonômico e palinotaxonômico da família Passifloraceae s.s. no Parque Estadual da Cachoeira da Fumaça, Alegre/Ibitirama, Espírito Santo, ampliando assim, o conhecimento da diversidade de espécies de Passifloraceae s.s. no estado do Espírito Santo, e consequentemente do Brasil.

\section{Material e Métodos}

O Parque Estadual Cachoeira da Fumaça (PECF) está localizado entre as coordenadas geográficas de $20^{\circ} 10^{\prime}$ e $21^{\circ} 05^{\prime} \mathrm{S}$ e $40^{\circ} 50^{\prime}$ e $41^{\circ} 50^{\prime} \mathrm{W}$, na divisa dos municípios de Alegre e Ibitirama, situado na região do Caparaó, no estado do Espírito Santo (Fig. 1), com área aproximadamente de 162,5 ha, encontrando-se sob domínio da Mata Atlântica, sendo que a formação florestal existente é do tipo Floresta Estacional Semidecidual. O Parque protege nascentes e remanescentes de um trecho conservado do rio Braço Norte Direito, afluente do rio Itapemirim, e apresenta como atração principal, uma queda d'água de $144 \mathrm{~m}$ de altura que forma uma cortina de fumaça, dando origem ao nome do Parque. A região é formada por fragmentos florestais de mata ciliar, vegetação rupestre, brejo herbáceo, vegetação exótica, áreas em diferentes estágios de regeneração natural, assim como áreas ocupadas por atividade agrícola. O clima é tropical, com pluviosidade média anual em torno de $1.200 \mathrm{~mm}$, período de chuva de novembro a março e de estiagem de maio a setembro, e temperatura média de aproximadamente $23{ }^{\circ} \mathrm{C}$ (IDAF 2000; IEMA 2017).

As coletas foram realizadas em toda a extensão do PECF, em caminhadas aleatórias, segundo Filgueiras et al. (1994), de janeiro de 2010 a dezembro de 2011, e todo material preservado segundo normas

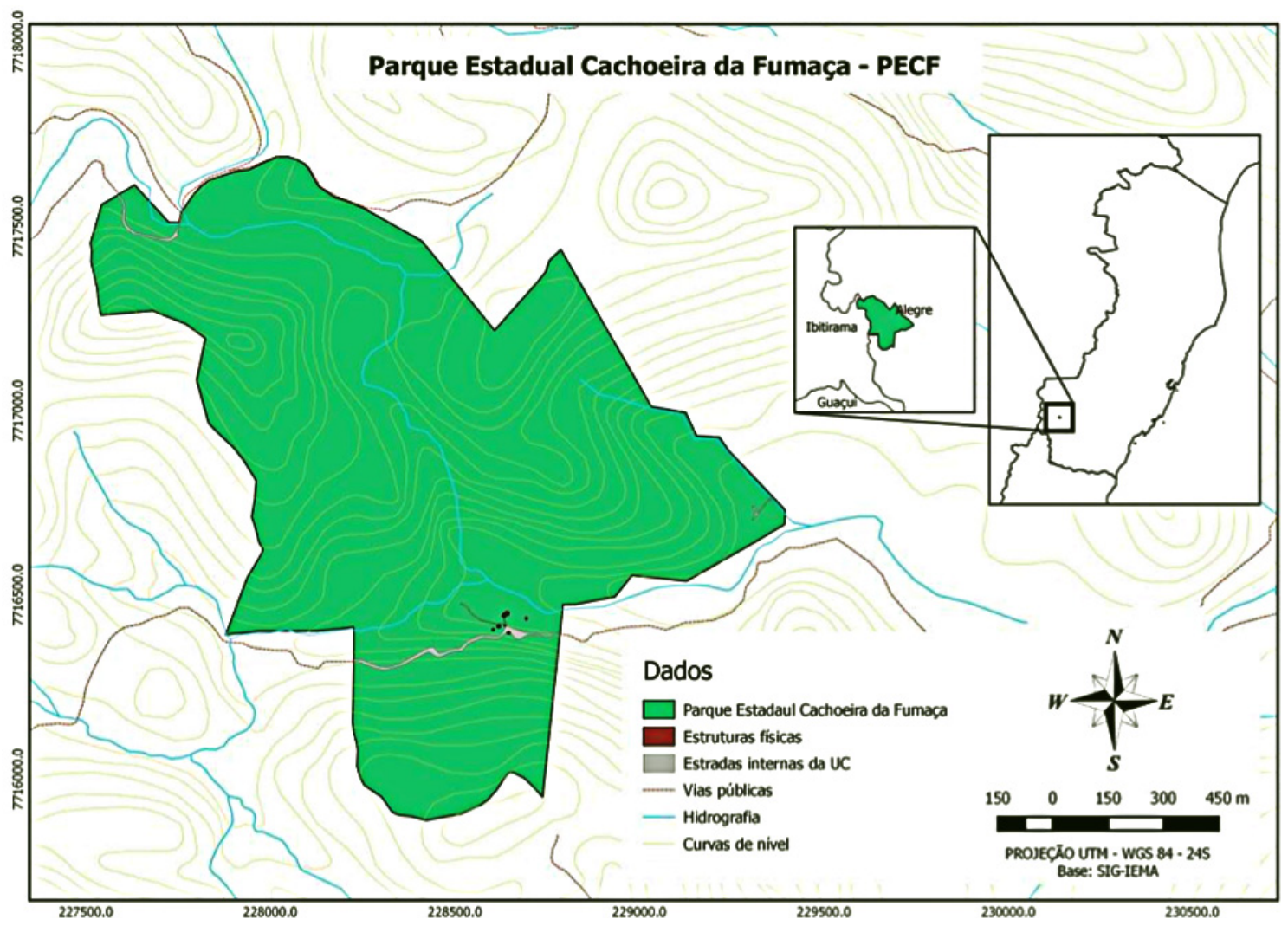

Figura 1 - Mapa da área total do Parque Estadual da Cachoeira da Fumaça, Alegre e Ibitirama, Espírito Santo, Brasil, delimitado em verde, retirado de IEMA 2017.

Figure 1 - Map of the total area of Parque Estadual da Cachoeira da Fumaça, Alegre and Ibitirama, Espírito Santo, Brazil, delimited in green, taken from IEMA 2017. 
usuais em taxonomia vegetal (Fidalgo \& Bononi 1989). Os exemplares coletados foram depositados no VIES (Herbário da Universidade Federal do Espírito Santo - subcuradoria Jerônimo Monteiro), cuja sigla está de acordo com Thiers (continuously updated). Além disso, foram utilizados materiais adicionais de áreas próximas à estudada, para completar a descrição das espécies, quando estas se encontravam sem flor ou fruto.

As análises morfológicas com identificação do material coletado foram realizadas através de consultas à bibliografia especializada. Para realizar a descrição dos caracteres vegetativos, florais e frutíferos foram adotados os conceitos de Harrington \& Durrell (1957), Radford et al. (1974), Rizzini (1977), Stearn (1995), Barroso et al. (1999), Peréz-Cortéz et al. (2002).

As análises palinológicas foram realizadas com material coletado na área de estudo e fixado em metanol ácido acético (3:1), nos laboratórios de Biotecnologia do Centro de Ciências Agrárias e Engenharias da Universidade Federal do Espírito Santo (CCAE/UFES) e de Palinologia do Museu Nacional da Universidade Federal do Rio de Janeiro (MN/UFRRJ).

Os grãos de pólen foram acetolisados seguindo o protocolo de Erdtman (1960), medidos até sete dias após sua preparação (Salgado-Labouriau 1973) e fotomicrografados em microscopia de luz. Nas amostras foram medidos o diâmetro polar (DP) e o diâmetro equatorial (DE) de 25 grãos de pólen de cada espécie em vista equatorial, calculando-se a média aritmética. A terminologia adotada seguiu Barth \& Melhem (1988) e Punt et al. (2007).

\section{Resultados e Discussão}

Tratamento taxonômico

Foram encontradas para família Passifloraceae s.s. seis espécies de Passiflora, representadas por dois subgêneros, duas espécies de Decaloba e quatro de Passiflora.

Passiflora L., Sp. P1.1: 955. 1753.

Trepadeiras herbáceas com caule cilíndrico, quadrangular, liso ou estriado, com gavinhas axilares. Estípulas lanceoladas, foliáceas, linearfalcadas, linear-subuladas ou subfalcadas. Pecíolo com ou sem glândulas, sésseis ou pediceladas. Folhas simples alternas, inteiras ou 2-3-lobadas, membranáceas a cartáceas, ápice agudo a obtuso, mucronado, base obtusa, cordada ou cuneada, margem inteira a levemente serreada. Brácteas verticiladas ou alternas, lanceoladas, lineares, subuladas, ovaladas, oblongas ou obovadas. Flores solitárias ou aos pares; sépalas oblongas, oblongolanceoladas, oblongo-lineares, ápice obtuso, agudo ou corniculado; pétalas oblongas, oblongolanceoladas, oblongo-lineares, ápice agudo a obtuso; corona com 1-5 séries de filamentos; opérculo membranoso, cartáceo, filamentoso ou plicado; límen cupuliforme ou anelar; grãos de pólen médios a grandes, isopolares, prolato-esferoidais, oblatoesferoidais ou suboblatos, 6-colpados, 12-colpados ou 6-colporados, exina heterorreticulada com muros sinuosos ou retos; ovário oblongo, ovado, obovado ou globoso. Frutos globosos, elipsoidais, oblongoelipsoides, oblongo-ovados ou ovado-elipsoidais; sementes ovadas, elipsoidais ou cordiformes, testa reticulada, foveolada ou transversalmente sulcada.

\section{Chave de identificação das espécies de Passifloraceae s.s. do Parque Estadual da Cachoeira da Fumaça, Alegre / Ibitirama, Espírito Santo, Brasil}

1. Folhas com pecíolos com glândulas; sementes com testa foveolada ou reticulada 2 (Subgênero Passiflora)

1'. Folhas com pecíolos sem glândulas; sementes com testa transversamente sulcada 5 (Subgênero Decaloba)

2. Folhas com pecíolos com 3-8 glândulas .............................................. Passiflora amethystina

2'. Folhas com pecíolos com 1-2 pares de glândulas ............................................................. 3

3. Caules quadrangulares ........................................................................ Passiflora alata

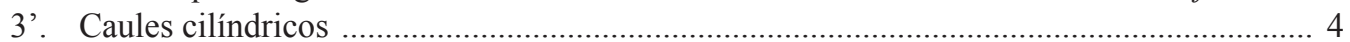

4. Flores com corona com 5 séries de filamentos ............................... Passiflora edulis

4'. Flores com corona com 2 séries de filamentos ............................ Passiflora speciosa

5. Lâminas foliares com ocelos; brácteas linear-subuladas; flores com corona com 1 série de filamentos; frutos bagas Passiflora porophylla

5'. Lâminas foliares sem ocelos; brácteas ausentes; flores com corona com 2 séries de filamentos; frutos cápsulas Passiflora capsularis 
1. Passiflora alata Curtis, Bot. Mag. 2: t. 66 . 1788. Figs. 2a; 3a-c; Tab. 1

Trepadeiras glabras, com caules quadrangulares, alados, castanho. Estípulas 0,4-0,5 × 1-1,3 cm compr., lanceoladas, ápice agudo, base obtusa, margem inteira. Folhas com pecíolos 2-3 cm compr., 2 pares de glândulas pediceladas; lâminas foliares inteiras 5,6-8,5 × 11,6-16 cm, ovadas a elípticas, membranáceas a cartáceas, ápice obtuso, mucronado, base obtusa, margem inteira, oceolos ausentes. Pedúnculos 1,5-3,5 cm compr. Brácteas 1,6-2,5 × 0,8-2 $\mathrm{cm}$, membranáceas, lanceoladas a lineares, ápice agudo, base arredondada, margem inteira, verticiladas. Flores solitárias, avermelhadas; pedicelos 1,4-1,8 cm compr.; sépalas 3,6-4,3 $\times$ 1,3-1,6 cm, oblongas, ápice obtuso, face externa verde com carena, face interna vermelhadovinácea com bordas branco-arroxeadas, glabras; pétalas $3,8-4,9 \times 1,6-1,7 \mathrm{~cm}$, oblongas, ápice obtuso, avermelhadas; corona com 4 séries de filamentos, as duas externas com filamentos 3-4,5 cm compr., filiformes, bandeados de roxo e branco, séries internas $0,2-0,4 \mathrm{~cm}$, filiformes,; opérculo membranoso; límen anelar; androginóforo 1,7-1,9 cm compr.; filete ca. 0,6 cm compr.; antera ca. 1,2 cm compr., grãos de pólen grandes, oblato-esferoidais, 6-colpados, diâmetro polar $62,5-77,5 \mu \mathrm{m}$, diâmetro equatorial $62,5-87,5$ $\mu \mathrm{m}$, exina reticulada; ovário ca. $1 \mathrm{~cm}$ compr., oblongo, glabro. Frutos bagas 8-8,5 ×4,5-5,1 cm, ovado-elipsoidais; sementes $0,6-0,7 \mathrm{~cm}$ compr., cordiformes, alveoladas, testa foveolada.

Material examinado: Alegre, Trilha Maria Campagnaro, 20'37'26"S, 41'36'24"O, 28.VIII.2010, bot. e fl., M.A. Milward-de-Azevedo et al. 286 (VIES); Trilha do Sr. Jaci, 203'51"S, 4136'03"O, 11.XII.2010, fr., M.A. Milward-de-Azevedo et al. 434 (VIES).

Material adicional: BRASIL. ESPÍRITO SANTO: Alegre, Área experimental CCA-UFES, Coleção de trabalho do Centro de Ciências Agrárias do Espírito Santo, $21^{\circ} 15^{\prime} 03^{\prime \prime}$ 'S $41^{\circ} 49^{\prime} 15^{\prime}$ 'O, 28.X.2011, fl. e fr., K.F. Borges 03 (VIES).

Passiflora alata é diferenciada das demais espécies por apresentar expansões aladas no caule, folhas com dois pares de glândulas nos pecíolos, lâminas foliares inteiras e flores avermelhadas. Apresenta-se como uma espécie de interesse econômico por seus frutos comestíveis e adocicados, flores de coloração vistosa e aroma doce. No PECF foi encontrado em beira de estrada e ao longo das trilhas internas do parque.
2. Passiflora amethystina Mikan, Delect. Fl. et Faun.Bras. 4. 1820 (1825).

Figs. 2b; 3p-r; Tab. 1

Trepadeiras glabras, com caules cilíndricos, verde a vináceo. Estípulas 1,4-2,8 × 0,3-1,2 $\mathrm{cm}$ compr., foliáceas, ovado-oblongas, ápice agudo-mucronado, base arredondada, margem inteira. Folhas com pecíolos 2-6 cm compr., 3-8 glândulas pediceladas; lâminas foliares 3-lobadas, membranáceas a cartáceas, nervuras centrais 4,5$5,2 \mathrm{~cm}$ compr., nervuras laterais 3,9-4,6 cm compr., distância entre ápices das nervuras laterais 7-7,9 cm compr., distância entre nervura central e lateral 3,6-4 cm compr., ápice agudo-obtuso, base obtusa, margem inteira, presença de glândulas nos sinus e base, oceolos ausentes. Pedúnculos $4-5 \mathrm{~cm}$ compr. Brácteas $0,3-0,6 \times 1-2,5 \mathrm{~cm}$, membranáceas, lanceoladas, ápice agudo, base oblíqua, margem inteira, verticiladas. Flores solitárias, azuis a roxas; pedicelos 0,1-0,2 cm compr.; sépalas 2,6-3,3 × 0,9-1,1 cm, oblongo-lanceoladas, ápice corniculado, esverdeadas, glabras; pétalas 2,8-3,6 × 1-1,1 cm, oblongas, ápice obtuso, azuis a roxas; corona com 4 séries de filamentos, séries externas filamentos 1,6-1,8 cm compr., filiformes, bandeadas de roxo e branco, séries internas $0,3-0,7$ cm compr., filiformes; opérculo filamentoso; límen cupuliforme; androginóforo 1,5-2,5 cm compr.; filetes ca. $0,7 \mathrm{~cm}$ compr.; anteras $0,5-1 \mathrm{~cm}$ compr.; grãos de pólen grandes, esferoidais, 6-colpados, diâmetro polar ca. $77 \mu \mathrm{m}$, diâmetro equatorial ca. $77 \mu \mathrm{m}$, exina reticulada; ovário ca. $0,9 \mathrm{~cm}$ compr., oblongo, piloso. Frutos bagas $6-7 \times 2,3-2,8 \mathrm{~cm}$, oblongos a elipsóides; sementes ca. $0,5 \mathrm{~cm}$ compr., ovaladas, testa foveolada.

Material examinado: Alegre, Trilha do Sr. Jaci, $20^{\circ} 37^{\prime} 51$ "S, 41036'15"'O, 11.VI.2010, bot, fl. e fr., M.A. Milward-de-Azevedo et al. 261 (VIES); 2037'52"S, 4136'07'O, 11.XII.2010, fl., M.A. Milward-de-Azevedo et al. 439 (VIES); trilha das bananeiras, $21^{\circ} 03^{\prime} 99^{\prime \prime} \mathrm{S}$, $42^{\circ} 00^{\prime} 58^{\prime}$ 'O, 29.X.2011, fl., K.F. Borges $01 \&$ H.G. Castro (VIES).

Passiflora amethystina é diferenciada das demais espécies por apresentar folhas com pecíolos com 3-8 glândulas pediceladas, lâminas foliares 3 lobadas e flores azuis a roxas. No PECF foi encontrado ao longo das trilhas internas do parque. Foi avaliada pelo CNCFlora (2017) como LC (menos preocupante).

\section{Passiflora capsularis L., Sp. P1. 2: 957. 1753.}

Figs 2c; 3d-f; Tab. 1

Trepadeiras pubescentes, com caules estriados, castanho. Estípulas ca. 0,2 $\times 0,1 \mathrm{~cm}$, 

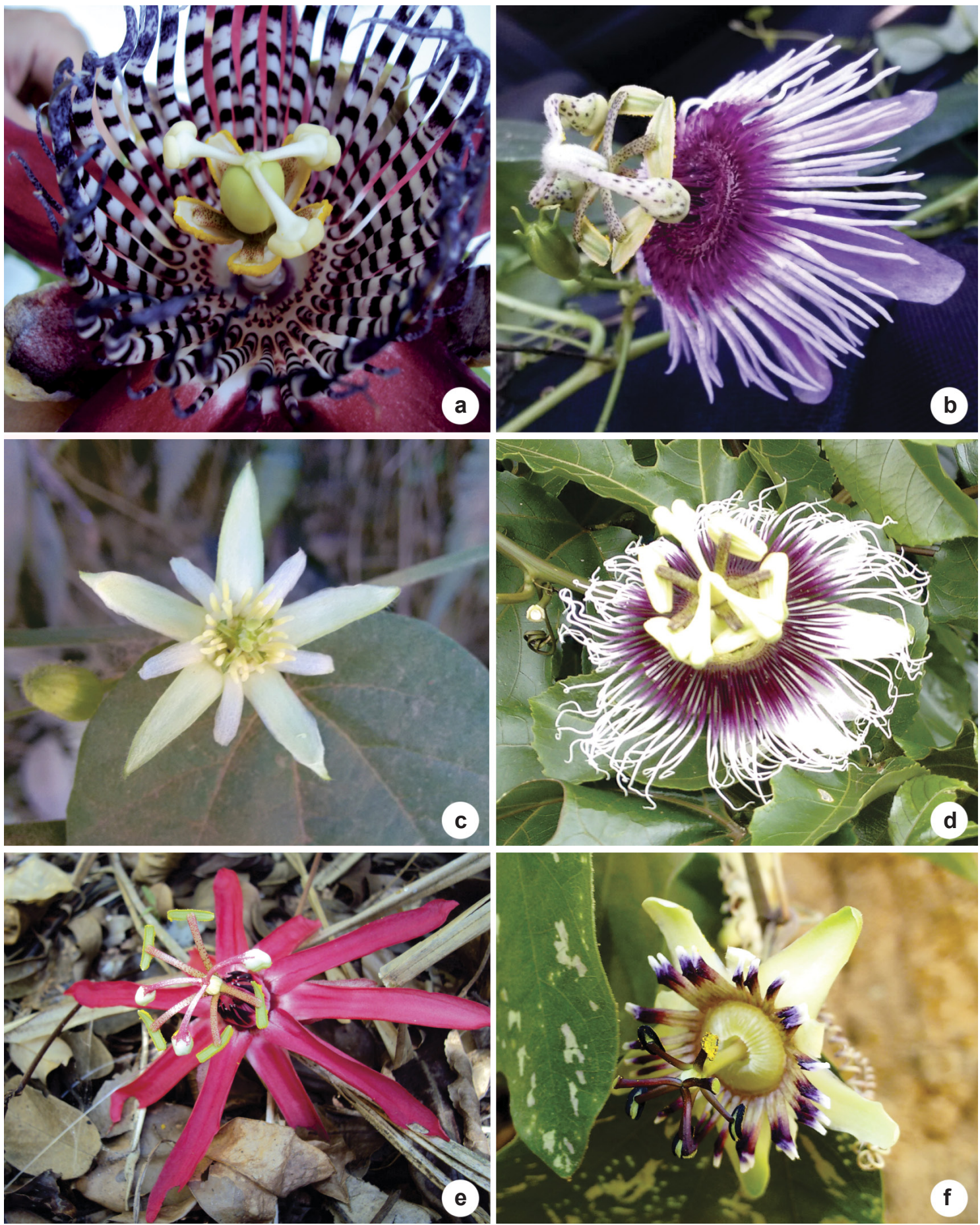

Figura 2 - Espécies de Passiflora do Parque Estadual Cachoeira da Fumaça, Espírito Santo, Brasil - a. Passiflora alata. b. Passiflora amethystina. c. Passiflora capsularis. d. Passiflora edulis. e. Passiflora speciosa. f. Passiflora porophylla.

Figure 2 - Passiflora species from Parque Estadual Cachoeira da Fumaça, Espírito Santo, Brazil. - a. Passiflora alata. b. Passiflora amethystina. c. Passiflora capsularis. d. Passiflora edulis. e. Passiflora speciosa. f. Passiflora porophylla. 


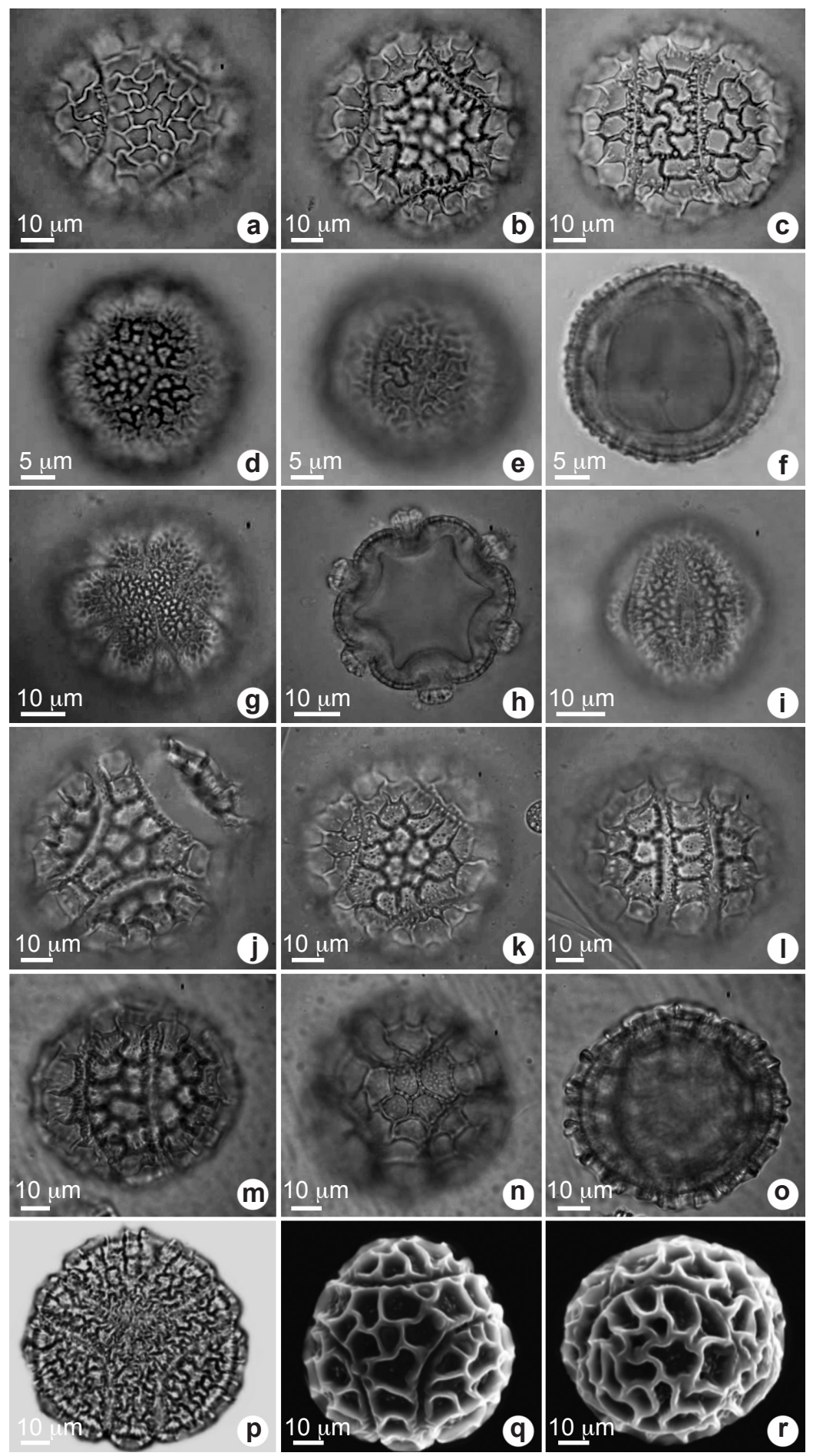

Figura 3 - Fotomicrografias dos grãos de pólen de espécies de Passiflora do Parque Estadual Cachoeira da Fumaça, Espírito Santo, Brasil - a-c. Passiflora alata. d-f. Passiflora capsularis. g-i. Passiflora porophylla. j-1. Passiflora speciosa. m-o. Passiflora edulis. p. Passiflora amethystina, retirado do trabalho de Evaldt et al. (2011). q-r. Microscopia de varredura de Passiflora amethystina, retirados do trabalho de Evaldt et al. (2011).

Figure 3 - Photomicrographs of pollen grains in the species of Passiflora from Parque Estadual Cachoeira da Fumaça, Espírito Santo, Brazil - a-c. Passiflora alata. d-f. Passiflora capsularis. g-i. Passiflora porophylla. j-1. Passiflora speciosa. m-o. Passiflora edulis. p. Passiflora amethystina, removed from Evaldt et al. (2011). q-r.Electron photomicrographs of Passiflora amethystina, removed from Evaldt et al. (2011). 
Tabela 1 - Caracterização morfológica dos grãos de pólen $(\mathrm{n}=25)$ de Passiflora do Parque Estadual da Cachoeira da Fumaça, Espírito Santo, Brasil.

Table 1 - Morphological characterization of pollen grains $(n=25)$ of Passiflora from Parque Estadual Cachoeira da Fumaça, Espírito Santo, Brazil.

\begin{tabular}{lccccc}
\hline Espécies & Forma & DP* & DE* & DP/DE* & Abertura \\
\hline Passiflora alata & oblato-esferoidais & $62,5-77,5$ & $62,5-87,5$ & 0,91 & 6-colpados \\
Passiflora amethystina & esferoidais & 77,0 & 77,0 & 1 & 6-colpados \\
Passiflora capsularis & oblato-esferoidais & $35,0-40,0$ & $35,0-42,5$ & 0,94 & $12-c o l p a d o s$ \\
Passiflora edulis & suboblatos & $60-62,5$ & $67,5-75$ & 0,85 & 6 -colpados \\
Passiflora porophylla & prolato-esferoidais & $50,0-62,5$ & $47,5-57,5$ & 1,06 & 12-colporados \\
Passiflora speciosa & oblato-esferoidais & $67,5-87,5$ & $77,5-95,0$ & 0,94 & 6-colpados \\
\hline
\end{tabular}

DP: Diâmetro Polar; DE: Diâmetro Equatorial. *Valores em $\mu \mathrm{m}$.

linear-falcadas, ápice caudado, base truncada, margem inteira. Folhas com pecíolos $0,9-2 \mathrm{~cm}$ compr., glândulas ausentes; lâminas foliares 2-lobadas, nervura central 1,9-5 cm compr., nervuras laterais 5,4-10,2 cm compr., distância entre os ápices das nervuras laterais 5,2-5,6 cm compr., distância entre nervura central e lateral 1,4-2,9 cm compr., membranáceas a cartáceas, ápice agudo, base cordada, margem inteira, oceolos ausentes. Pedúnculos 2,4-4,8 cm compr. Brácteas ausentes. Flores solitárias, brancas; pedicelos 0,3-0,4 cm compr.; sépalas $1,1-2,5 \times$ $0,2-0,4 \mathrm{~cm}$, oblongas, ápice agudo, verde-claro, pubescentes; pétalas $0,5-1 \times 0,2-0,3 \mathrm{~cm}$, oblongolanceoladas, ápice agudo, brancas; corona com 2 séries de filamentos, série externa 1,1-1,4 cm compr., filiformes, branca, série interna ca. $0,2 \mathrm{~cm}$ compr., capilares; opérculo plicado; límen anelar; androginóforo $0,6-0,9 \mathrm{~cm}$ compr.; filete ca. 0,4 cm compr.; antera $0,1-0,2 \mathrm{~cm}$ compr.; grãos de pólen médios, oblato-esferoidais, 12-colpados, diâmetro polar 35-40 $\mu \mathrm{m}$, diâmetro equatorial 35-42,5 $\mu \mathrm{m}$; exina reticulada; ovário $0,3-0,4 \mathrm{~cm}$ compr., hexagonal a ovado. Frutos capsulares ca. $4,2 \times 1,8 \mathrm{~cm}$, hexagonais a elipsoidais, marromavermelhados quando maduro; sementes $0,2-0,4$ cm compr., elipsoidais, testa transversamente sulcada.

Material examinado: Alegre, Trilha do Sr. Jaci, 203'51'S, 41'36'15'O, 11.VI.2010, M.A. Milwardde-Azevedo et al. 262 (VIES); área do Sr. Adalto de

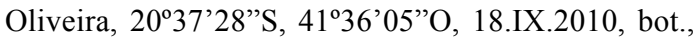
M.A. Milward-de-Azevedo et al. 313 (VIES); 2037'27'S, 41'36'01'O, 18.IX.2010, bot., M.A. Milward-de-Azevedo et al. 319 (VIES); 20³7’28”'S, 4136'01”O, 18.IX.2010, bot., M.A. Milward-de-Azevedo et al. 323 (VIES); 28.XI.2010, fl., M.A. Milward-de-Azevedo et al. 399 (VIES); 28.XI.2010, bot., fl. e fr., M.A. Milward-deAzevedo et al. 401 (VIES); estrada de acesso à trilha da Maria Luzia Campagnaro, 42 $02^{\prime} 19^{\prime \prime} \mathrm{S}, 21^{\circ} 03^{\prime} 07^{\prime \prime} \mathrm{O}$, 28.X.2011, fl. e fr., K.F. Borges 04 \& H.G. Castro (VIES).

Passiflora capsularis é diferenciada das demais espécies por apresentar os pecíolos e as lâminas foliares desprovidos de glândulas e oceolos, lâminas foliares bilobadas, brácteas ausentes e frutos capsulares. No PECF foi encontrado ao longo das trilhas internas do parque, e próximo a cachoeira, na zona de borrifo.

4. Passiflora edulis Sims, Bot. Mag. 45: t. 1989. 1818.

Figs. 2d; 3m-o; Tab. 1

Trepadeiras glabras, com caules cilíndricos, estriados, verde. Estípulas 0,2-0,4 × ca. 0,1 cm, lineares, ápice caudado, base truncada, margem inteira. Folhas com pecíolos 2-3,5 cm compr., 1 par de glândulas sésseis próximas à base da folha; lâminas foliares inteiras a 3-lobadas, nervuras central 8,7-12,6 cm compr., nervuras laterais 7,110,2 cm compr., distância entre ápices das nervuras laterais 8,3-12,2 cm compr., distância entre nervura central e lateral 4,2-6,1 cm compr., cartáceas, ápice agudo, base cordada, margem serreada, presença de glândulas nos sinus e base, oceolos ausentes. Pedúnculos 3-4,1 cm compr. Brácteas 2,3-2,5 × 1,4-1,5 cm, membranáceas, foliáceas, ovaladas a oblongas, ápice agudo, base obtusa a cordada, margem serreada, verticiladas. Flores solitárias, brancas com lilás; pedicelos $1,5-2,5 \mathrm{~cm}$ compr.; sépalas 2,2-3,2 × 0,8-1,2 cm, oblongas a lanceoladas, ápice obtuso, face externa verde e 
face interna branca, glabras; pétalas $2-3 \times 0,5-0,7$ $\mathrm{cm}$, oblongas, ápice obtuso, brancas; corona com 5 séries de filamentos, as duas séries externas com filamentos 1,2-2,5 cm compr., filiformes, violáceas na base, purpúrea na região mediana, branco no ápice, séries internas 0,15-0,26 cm compr., lineares; opérculo cartáceo; límen cupuliforme; androginóforo 1,6-2,3 cm compr.; filetes 0,7-1 cm compr.; anteras 1-1,2 cm compr.; grãos de pólen grandes, suboblatos, 6-colpados, diâmetro polar 60-62,5 $\mu \mathrm{m}$, diâmetro equatorial 67,5-75 $\mu \mathrm{m}$, exina reticulada com báculos; ovário $0,9-1,1$ cm compr., globoso. Frutos bagas 6-7,5 × 4,2-5,4 $\mathrm{cm}$, globosos, amarelo quando maduro; sementes 0,5-0,6 cm compr., ovadas, testa reticulada.

Material examinado: Alegre, área do sr. Adalto de Oliveira, 20³7'29''S, 4135'58'O, 28.XI.2010, fl., M.A. Milward-de-Azevedo et al. 403 (VIES).

Material adicional: BRASIL. ESPÍRITO SANTO: Alegre. Área experimental CCA-UFES, Coleção de trabalho do Centro de Ciências Agrárias do Espírito

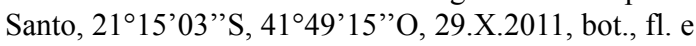
fr., K.F. Borges 05 (VIES).

Passiflora edulis pode ser diferenciada das demais espécies por apresentar folhas com pecíolos com um par de glândulas sésseis, lâminas foliares inteiras a 3 lobadas com margem serreada e flores brancas com filamentos da corona de coloração roxa. No PECF foi encontrado próximo a área de pasto. Espécie mais cultivada dentro do gênero. Possui alto valor econômico, e devido ao sucesso de sua produção, novas variedades têm sido descritas. Possui potencial para as indústrias de cosméticos, indústria alimentícia, ornamental e medicinal. É caracterizada por seus frutos grandes com grande volume de polpa (Bernacci et al. 2003). Foi avaliada pelo CNCFlora (2017) como LC (menos preocupante).

5. Passiflora porophylla Vell., Fl. Flumin. Icon.9: t. 82.1827 (1831).

Fig. $2 \mathrm{f}$

Trepadeiras glabras, com caules estriados, complanados, esverdeados. Estípulas $0,1-0,2 \times$ ca. $0,05 \mathrm{~cm}$ compr., linear-subuladas a subfalcadas, ápice caudado, base truncada, margem inteira. Folhas com pecíolos 0,9-3,5 cm compr., glândulas ausentes; lâminas foliares 2-lobadas a incipiente 3-lobadas, nervuras central 2,3-6,9 cm compr., nervuras laterais 2,1-7,6 cm compr., distância entre ápice das nervuras laterais $2,8-7,2 \mathrm{~cm}$ compr., distância entre nervura central e lateral 1,2-3,6 cm compr., membranáceas a cartáceas, ápice mucronado a agudo-obtuso, base obtusa, margem inteira, oceolos entre as nervuras laterais.
Pedúnculos 2,8-5,6 cm compr. Brácteas 0,1-0,3× ca. $0,05 \mathrm{~cm}$, linear-subuladas, ápice caudado, base truncada, margem inteira, alternas. Flores solitárias ou aos pares, brancas com lilás; pedicelos $0,2-0,3$ cm compr.; sépalas 1,6-1,9 × 0,3-0,6 cm compr., oblongo-lanceoladas, ápice obtuso, creme, glabras; pétalas $0,9-1,5 \times 0,2-0,4 \mathrm{~cm}$, ovalado-lanceoladas, ápice agudo, brancas; corona unisseriada $0,6-1 \mathrm{~cm}$ compr., dolabriformes, ápice e base brancos, região mediana roxa; opérculo plicado; límen anular; androginóforo $0,6-1 \mathrm{~cm}$ compr.; filetes $0,7-1$ cm compr.; anteras $0,4-0,6$ cm compr.; grãos de pólen grandes, prolato-esferoidais, 12-colporados, diâmetro polar 50-62,5 $\mu \mathrm{m}$, diâmetro equatorial $47,5-57,5 \mu \mathrm{m}$, exina reticulada; ovário $0,3-0,5$ $\mathrm{cm}$ compr., obovado. Frutos bagas ca. $2 \times 1,5$ $\mathrm{cm}$, globosos, nigrescente; sementes $0,3-0,5 \mathrm{~cm}$ compr., elipsoidais, testa transversalmente sulcada. Material examinado: Alegre, 29.X.2011, bot., fl. e fr., M.A. Milward-de-Azevedo 467 et K.F. Borges (VIES); estrada de acesso à trilha da Maria Luzia Campagnaro,

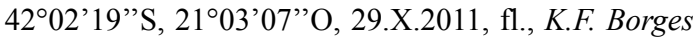
\& H.G. Castro 07 (VIES).

Passiflora porophylla é diferenciada das demais espécies por apresentar os pecíolos desprovidos de glândulas, as lâminas foliares são bilobadas com oceolos entre as nervuras laterais, as flores apresentam uma série de filamentos da corona, dolabriformes e de coloração roxa. No PECF foi encontrado em beira de estrada. Foi avaliada pelo CNCFlora (2017) como LC (menos preocupante).

6. Passiflora speciosa Gardner, Field. Sert. Pl.: t. 17. 1844 Figs. 2e; 3j-1; Tab. 1

Trepadeiras pubescentes, com caules cilíndricos, estriados, ferrugíneos. Estípulas ca. $0,2 \times 0,1 \mathrm{~cm}$, linear-subuladas, ápice caudado, base truncada, margem inteira. Folhas com pecíolos 0,6-0,9 cm compr., 1 par de glândulas sésseis na base; lâminas foliares 3-lobadas, nervuras central $4,6-7,5 \mathrm{~cm}$ compr., nervuras lateral $2,2-7,1 \mathrm{~cm}$ compr., distância entre ápices das nervuras laterais 2,8-7,8 cm compr., distância entre nervura central e lateral 3,3-4 cm compr., cartáceas, ápice agudo a mucronado, base cuneada, margem serreada, oceolos ausentes. Pedúnculos 5,4-10,9 cm compr. Brácteas 3,2-5 × 0,5-1,6 cm, obovadas, ápice agudo, base aguda, margem serreada verticiladas. Flores solitárias, avermelhadas; pedicelos $5-10$ com compr.; sépalas 4,4-5,6 $\times 0,5-0,9 \mathrm{~cm}$, oblongolineares, ápice agudo, róseas, pubescentes; pétalas 4-4,6 × 0,6-0,8 cm, oblongo-lineares, ápice agudo, 
róseas; corona com 2 séries de filamentos, série externa 0,9-1 cm compr., filiformes a lanceolados, violáceos da região mediana para o ápice, série interna 0,3-0,7 cm compr., filiformes; opérculo membranáceo, plicado; límen cupuliforme; androginóforo 2,5-3 cm compr.; filetes ca. 1,2 cm compr.; anteras 0,6-0,8 cm compr.; grãos de pólen grandes, oblato-esferoidais, 6-colpados, diâmetro polar 67,5-87,5 $\mu \mathrm{m}$, diâmetro equatorial 77,5-95 $\mu \mathrm{m}$; exina reticulada; ovário $1-1,3 \mathrm{~cm}$ compr., oblongo-elipsoidal, pubescente. Frutos bagas ca. 4,6 × 3,7 cm, oblongo-ovalados, esverdeado com listras longitudinais rosadas, pubérulos; sementes 0,3-0,4 cm compr., ovalados, testa reticulada.

Material examinado: Alegre, trilha da Maria Luzia Campagnaro, 20³7'24'S, 41³6'25'O, 28.VIII.2010, bot. e fl., M.A. Milward-de-Azevedo et al. 299 (RB, VIES); 20³7'24'’S, 41'36'25'O, 29.X.2011, fl. e fr., K.F. Borges 09 (VIES).

Passiflora speciosa é diferenciada das demais espécies por apresentar folhas pecioladas com um par de glândulas sésseis, lâminas foliares 3 lobadas com margem serreadas, e flores róseoavermelhadas. No PECF foi encontrado ao longo das trilhas internas do parque.

\section{Palinologia}

Com relação ao estudo dos grãos de pólen, foram analisados apenas cinco das seis espécies ocorrentes no PECF: P. alata-M.A. Milward-deAzevedo et al. 434 (VIES); P. capsularis - M.A.
Milward-de-Azevedo et al. 401 (VIES); P. edulis - M.A. Milward-de-Azevedo et al. 403 (VIES); P. porophylla-M.A. Milward-de-Azevedo 467 et K.F. Borges (VIES); e P. speciosa - M.A. Milward-deAzevedo et al. 299 (RB, VIES). Os dados de $P$. amethystina foram retiradas do trabalho de Evaldt et al. (2011), pois o material em flor e botão coletado e incluído no Herbário VIES foi destruído por pragas naturais, em virtude dos botões e flores serem muito palatáveis.

Os táxons possuem grãos de pólen médios (P. capsularis) a grandes ( $P$. alata, P. porophylla, $P$. amethystina, $P$. edulis e $P$. speciosa), isopolares, prolato-esferoidais ( $P$. porophylla), oblato-esferoidais (P. alata, P. capsularis e P. speciosa), suboblatos ( $P$. edulis) ou esferoidais ( $P$. amethystina), 6-colpados (P. alata, P.amethystina, P. edulis e P. speciosa), 12-colpados (P. capsularis) ou 12-colporados $(P$. porophylla), todos com exina heterorreticulada (Fig. 3; Tab. 1). A ornamentação da exina apresenta retículos com muros sinuosos em $P$. alata, $P$. amethystina, $P$. capsularis, $P$. edulis e $P$. speciosa, e retículos com muros retos em $P$. porophylla.

Com base nesses dados foi possível apresentar uma chave de identificação das espécies estudadas, esses resultados corroboram com a chave proposta pelos caracteres do tratamento taxonômico.

A forma, o valor de diâmetro polar, valor de diâmetro equatorial e o tipo de abertura do grão de pólen das espécies estão descritos na Tabela 1 .

\section{Chave polínica de identificação das espécies de Passifloraceae s.s. ocorrentes no Parque Estadual da Cachoeira da Fumaça, Espírito Santo, Brasil}

1. Grãos de pólen colporados Passiflora porophylla

1'. Grãos de pólen colpados 2

2. Grãos de pólen 12-colpados .................................................................. Passiflora capsularis

2'. Grãos de pólen 6-colpados 3

3. Grãos de pólen suboblato .................................................................... Passiflora edulis

3'. Grãos de pólen oblato-esferoidais a esferoidais

4. Grãos de pólen esferoidais Passiflora amethystina

4'. Grãos de pólen oblato-esferoidal Passiflora alata e Passiflora speciosa

Na chave polínica as espécies Passiflora alata e $P$. speciosa não se diferenciam entre si, os grãos de pólen são morfologicamente muito semelhantes, não apresentando características polínicas diagnósticas para separá-las entre si, porém a região do apocolpo é menor em $P$. speciosa. Estas duas espécies pertencem ao subgênero Passiflora, por isso sua grande afinidade. Apesar dessa semelhança polínica, estas duas espécies constituem táxons autônomos, sendo distintos por características morfológicas vegetativas e reprodutivas.

Passiflora capsularis e P. porophylla pertencem ao subgênero Decaloba, nestas espécies a morfologia polínica mostrou-se importante para separa-las no mesmo grupo, pois apresentam pólen 12-colpados e 12-colporados, respectivamente. 
Em seu estudo, Presting (1965) descreveu, dentre outros, os grãos de pólen das espécies $P$. alata como 4-colpados, $P$. amethystina e $P$. porophylla como 6-colporados, P. edulis como 10-colpados e P. capsularis como 12-colporados. Estes resultados assemelham-se aos encontrados no presente estudo para as espécies $P$. amethystina e $P$. porophylla no que se refere a forma e a ornamentação da sexina. Com relação ao número de colpos, os resultados de Presting (1965) diferem dos que foi aqui encontrado: P. alata, P. edulis e $P$. amethystina com pólen 6-colpados, $P$. capsularis com pólen 12-colpados e $P$. porophylla com pólens 12-colporados, esta diferença deve-se a dificuldade de interpretação dos pseudopérculos.

Milward-de-Azevedo et al. (2004, 2010, 2014) analisaram espécies do subgênero Decaloba, entre elas $P$. capsularis e $P$. porophylla, mostrando que os grãos de pólen desse grupo possuem grande importância para distinguir as espécies, pois apresentam características diagnósticas em nível específico. Os resultados obtidos no presente trabalho foram semelhantes no que se refere a forma, tamanho e ornamentação da exina de $P$. porophylla. Já $P$. capsularis apresentou tamanho de grão de pólen médio, estando fora da faixa de variação de tamanho e forma dos espécimes analisados por Milward-de-Azevedo et al. (2004, 2010, 2014).

Araújo \& Santos (2004) analisaram e estabeleceram tipos polínicos para as espécies de Passiflora ocorrentes na Chapada Diamantina, Bahia, entre elas, $P$. alata. Os resultados obtidos no presente trabalho corroboram o número de colpos, a forma e a ornamentação da exina, porém o tamanho dos grãos de pólen aqui analisado é maior. Barrios et al. (2005) caracterizaram os grãos de pólen dos gêneros Dilkea e Passiflora e seus subgêneros, algumas características corroboram com o atual estudo.

As aberturas dos grãos de pólen de $P$. alata, $P$. amethystina, $P$. capsularis e $P$. edulis foram analisadas por Dettke \& Santos (2009). Para $P$. capsularis, os autores descreveram seus grãos de pólen como 12-colporados, mesmo resultado encontrado por Evaldt et al. (2011), diferindo do presente estudo, grãos de pólen com abertura do tipo 12-colpados. O resultado encontrado no presente estudo, corrobora com os resultados encontrados por Milward-de-Azevedo et al. (2010, 2014). Para as demais espécies analisadas, as aberturas dos grãos de pólen corroboram com os resultados encontrados por Dettke \& Santos (2009).
Diversas características polínicas têm se mostrado de valor diagnóstico específico para a taxonomia de Passifloraceae s.s. como pode ser observado em Milward-de-Azevedo et al. (2004, 2010, 2014) para o subgênero Decaloba, e em Mezzonato-Pires et al. $(2015,2017)$ para o subgênero Astrophea.

\section{Agradecimentos}

A profa. Dra. Ana Carolina Mezzonato-Pires por realizar as fotomicrografias dos grãos de pólen. Ao André Cunha, a confecção das pranchas.

\section{Referências}

APG IV - Angiosperm Phylogeny Group (2016) An update of the Angiosperm Phylogeny Group classification for the orders and families of flowering plants: APG IV. Botanical Journal of the Linnean Society 181: $1-20$.

Araújo RCM \& Santos FAR (2004) Palinologia de Especies do Genero Passiflora L (Passifloraceae) da Chapada Diamantinaa, Bahia, Brasil. Sitientibus Série Ciências Biológicas 4: 37-42.

Barrios L, Caetano CM, Cardoso CI, D'eeckenbrugge GC, Arroyave JA \& Olaya CA (2005) Caracterización del pollen de especies de los géneros Passiflora y Dilkea. Acta Agronômica 54: 19-23.

Barroso GM, Morim MP, Peixoto AL \& Ichaso CLF (1999) Frutos e sementes: morfologia aplicada sistemática de dicotiledôneas. Universidade Federal de Viçosa, Viçosa. 443p.

Barth OM \& Melhen TS (1988) Glossário ilustrado de palinologia. UNICAMP, Campinas. 75p.

Bernacci LC, Vitta FA \& Bakker YV (2003) Passifloraceae. In: Wanderley MGL et al. (eds.) Flora fanerogâmica do estado de São Paulo. FAPESP, São Paulo. Vol. 3, pp. 247-274.

BFG - The Brazil Flora Group (2015) Growing knowledge: an overview of seed plant diversity in Brazil. Rodriguésia 66: 1085-1113.

CNCFlora - Centro Nacional de Conservação da Flora (2017) Lista vermelha - Passifloraceae. Disponível em <cncflora.jbrj.gov.br/portal/pt-br/listavermelha/ PASSIFLORACEAE $>$. Acesso em 3 fevereiro 2017.

Deginani NB \& Novara L (1999) Passifloraceae. Aportes Botanicos de Salta - Serie Flora 6: 1-24.

Dettke GA \& Santos RP (2009) Tipos de aberturas dos grãos de pólen de espécies de Passiflora L. (Passifloraceae). Acta Botanica Brasílica 23: 11191128.

Dutra VF, Alves-Araújo A \& Carrijo TT (2015) Angiosperm checklist of Espírito Santo: using eletronic tools to improve the knowledge of an Atlantic Forest biodiversity hotspot. Rodriguésia 66: 1145-1152. 
Erdtman G (1960) The acetolysis method. A revised description. Svensk Botanisk 54: 561-564.

Evaldt ACP, Bauermann SG, Cancelli RR, Acioli M \& Neves PCP (2011) Morfologia polínica de Passifloraceae Juss. ex Kunth. no Rio Grande do Sul, Brasil. Revista Brasileira de Biociências 9: 75-87.

Fidalgo O \& Bononi VLR (1989) Técnicas de coleta, preservação e herborização de material botânico. Instituto de Botânica, São Paulo. 62p.

Filgueiras TS, Brochado AL, Nogueira PG \& Guala GF (1994) Caminhamento: um método expedito para levantamentos florísticos qualitativos. Cadernos de Geociências 12: 39-43.

Fonseca GAB, Alger K, Pinto LP, Araújo M \& Cavalcanti R (2004) Corredores de biodiversidade: o Corredor Central da Mata Atlântica. In: Arruda MB \& Sá LFSN (eds.) Corredores ecológicos: uma abordagem integradora de ecossistemas no Brasil. IBAMA, Brasília. Pp. 47-65.

Harrington HD \& Durrell LW (1957) Key to common leaf surface. How to identify plants. The Swallow Press, Chicago. 203p.

IDAF - Instituto de Defesa Agropecuária e Florestal do Espírito Santo (2000) Plano de manejo do Parque Estadual Cachoeira da Fumaça. MMA, FNMA, Vitória. 42p.

IEMA - Instituto Estadual de Meio Ambiente e Recursos Hídricos (2017) Parque Estadual Cachoeira da Fumaça. Disponível em <https://iema.es.gov.br/ Media/iema/Downloads/GRN/2017.10.05\%20-\%20 Plano\%20Emergencial\%20UP PECF.pdf $>$. Acesso em 12 fevereiro 2017.

Judd WS, Campbell CS, Kellogg EA, Stevens PF \& Donoghue MJ (2009) Sistemática vegetal: um enfoque filogenético. Artmed, Porto Alegre. 632p.

Krosnick SE, Ford AJ \& Freudenstein JV (2009) Taxonomic revision of Passiflora subgenus Tetrapathea including the monotypic genera Hollrungia and Tetrapathea (Passifloraceae), and a new species of Passiflora. Systematic Botany 34: 375-385.

Macdougal JM \& Feuillet C (2004) Systematic. In: Ulmer T \& MacDougal JM (eds.) Passionflowers of the world. Timber Press, Portland. Pp. 27-31.

Mäder G, Lorenz-Lemke AL, Cervi AC \& Freitas LB (2009) Novas ocorrências e distribuição do gênero Passiflora L. no Rio Grande do Sul, Brasil. Revista Brasileira de Biociências 7: 364-367.

Mezzonato-Pires AC, Milward-de-Azevedo MA, Mendonça CBF \& Gonçalves-Esteves V (2015) Pollen morphology and detailed sexine Passiflora subgenus Astrophea (Passifloraceae). Plant Systematic Evolution 301: 2189-2202. DOI 10.1007/s00606-015-1223-0.
Mezzonato-Pires AC, Mendonça CBF, Milward-deAzevedo MA \& Gonçalves-Esteves V (2017) The systematic value of pollen morphology of Passiflora subgenus Astrophea (Passifloraceae). Phytotaxa 298: 1-19. DOI: 10.11646/phytotaxa.298.1.1.

Milward-de-Azevedo, MA, Gonçalves-Esteves V \& Baumgratz JFA (2004) Palinotaxonomia das especies de Passiflora L. subg. Decaloba (DC.) Rchb. (Passifl oraceae) no Sudeste do Brasil. Revista Brasileira de Botânica 27: 655-665.

Milward-de-Azevedo MA, Souza FC, Baumgratz JFA \& Gonçalves-Esteves V (2010) Palinotaxonomia de Passiflora L. subg. Decaloba (DC) Rchb. (Passifloraceae) no Brasil. Acta Botanica Brasilica 24: 133-145.

Milward-de-Azevedo MA, Souza FC, Gonçalves-Esteves V \& Kinoshita LS (2014) Palinotaxonomy of Passiflora section Xerogona (Passifloraceae). Phytotaxa 159: $1-10$.

Peréz-Cortéz S, Tillett S \& Escala M (2002) Estudio morfológico de la semilla de 51 especies del género Passiflora L. Acta Botánica Venezuelica 25: 67-96.

Presting D (1965) Zur morphologie der pollenkörner der Passifloraceen. Pollen et Spores 7: 193-247.

Punt W, Blackmore S, Nilsson S \& Le Thomas A (2007) Glossary of pollen and spore terminology. Review of Paleobotany and Palynology 143: 1-81.

Radford AE, Dickison WC, Massey JR \& Bell CR (1974) Vascular plant systematics. Harper e Row, New York. $891 \mathrm{p}$.

Rizzini CT (1977) Sistematização terminológica da folha. Rodriguésia 42: 103-125.

Salgado-Labouriau ML (1973) Contribuição à palinologia dos cerrados. Academia Brasileira de Ciências, Rio de Janeiro. 291p.

Santos JV, Nunes TS \& Conceição AS (2016) A família Passiloraceae na APA Serra Branca/Raso da Catarina, Jeremoabo, Bahia, Brasil. Biotemas 29: 11-23.

Souza WO, Machado JO, Tognella MMP \& Alves-Araújo A (2016) Checklist de angiospermas do Parque Estadual de Itaúnas, Espírito Santo, Brasil. Rodriguésia 67: 571-581.

Stearn WT (1995) Botanic latin: history, grammar, syntax, terminology and vocabulary. Timber Press, Portland. $560 \mathrm{p}$.

Thiers B [continuamente atualizado] Index Herbariorum: a global directory of public herbaria and associated staff. New York Botanical Garden's Virtual Herbarium. Disponível em <http://sweetgum.nybg.org/ih/>. Acesso em 12 fevereiro 2017.

UlmerT \& Macdougal JM(2004) Passiflora: Passionflowers of the world. Timber Press, Cambridge. 430p. 
